\title{
Design of micro/mini-wind-turbine(MWT) based Uninterrupted Power Supply(UPS) for domestic applications
}

\author{
Sisir Mazumder \\ Asstt.Prof.(Electrical Engineering), \\ Gurunanak Institute of Technology, Kolkata-700114 \\ Arindam Roy \\ Asstt.Prof.(EE), \\ Gurunanak Institute of Technology, Kolkata-700114
}

\begin{abstract}
This paper makes an innovative attempt to design and implement a Wind-turbine(VAWT i.e. Vertical Axis Wind Turbine) based Uninterrupted Power Supply(WT-UPS) for domestic applications so that use of conventional power could be reduced to some extent and hence saving the environment from $\mathrm{CO} 2$ emission. Winder power being a renewable source of energy could easily be tapped at the domestic level through installation of a DC Generator through gear box for speed transformation and hence charging Electric battery through a Voltage Regulator, and an inverter connecting the critical load in any domestic situation, and thus reducing the Electricity bills of the households. It is to be noted that WT-UPS is supposed to operate 24 hours a day and therefore having huge potential for storage of energy in Electrical batteries.

Key-words: Wind-turbines, Uninterrupted Power Supply, Renewable Sources of Energy, Electrical Storage Batteries, Vertical Axis Wind Turbine(VAWT), Gear Box, Voltage Regulators
\end{abstract}

\section{OBJECTIVES}

To conceptualize a modular design small $250 \mathrm{~W}$ output Wind Turbine UPS for every household so as to curtail electricity bills for every home anywhere in the world. The wind power available is truly infinite in magnitude and nature. We can calculate the average power available at any place by consulting data book on the subject and harness wind energy for a cleaner environment as well as cost reduction in electricity consumption. We tried to design a Vertical axis wind-turbine based UPS of low cost, low maintenance for a 24 hour operation.

Theoretical discussion about energy to be derived from vertical axis wind turbine:

From standard literature, the following equations are to be considered for design and development of the microwind-turbine based uninterrupted power supplies for each home. The equations use standard symbols. Total kinetic energy $(\mathrm{KE})$ intercepted by the turbine blades can be given by:

$$
\begin{aligned}
& \mathrm{KE}=\frac{1}{2}\left(\text { s.A. } \mathrm{V}^{3}\right) \text {. } \\
& \mathrm{A}=\frac{\pi \cdot \mathrm{D}^{2}}{4}, \mathrm{P}_{\mathrm{a}}=\frac{\pi \cdot \zeta \cdot \mathrm{D}^{2} \cdot \mathrm{V}^{3}}{8} \\
& \mathrm{~V}_{\mathrm{a}} \approx \mathrm{V}_{\mathrm{b}} \approx \mathrm{V}_{\mathrm{t}} \quad \varsigma=1.225 \mathrm{Kg} / \mathrm{m}^{3} \\
& \mathrm{P}_{\mathrm{av}}(\mathrm{t})=\frac{1}{2}\left(\text { s.A. } \mathrm{V}_{\mathrm{o}}^{3}(\mathrm{t})\right) \\
& \mathrm{F}_{x}=\left(\mathrm{P}_{a}-P_{b}\right) \cdot A=\text { s.A. } \cdot\left(\frac{V_{t}^{2}-V_{e}^{2}}{2 \cdot g \cdot e}\right) \\
& \mathrm{F}_{\mathrm{x}}=\Delta \cdot \dot{\mathrm{m} V} \mathrm{Vc} \\
& \dot{\mathrm{m}}=\mathrm{s} \cdot \mathrm{A} \cdot \mathrm{V}_{\mathrm{t}} \\
& \mathrm{F}_{\mathrm{x}}=\frac{1}{\mathrm{gc}} \cdot \zeta \cdot \mathrm{A} \cdot \mathrm{V}_{\mathrm{t}}\left(\mathrm{V}_{\mathrm{i}}-\mathrm{V}_{\mathrm{e}}\right) \\
& \Longrightarrow \mathrm{V}_{\mathrm{t}}=\frac{1}{2}\left(\mathrm{~V}_{\mathrm{i}}+\mathrm{V}_{\mathrm{e}}\right)
\end{aligned}
$$




$$
\begin{aligned}
& \mathrm{W}=\mathrm{KE}_{\mathrm{i}}-\mathrm{KE}_{\mathrm{t}}=\frac{\mathrm{V}_{\mathrm{i}}^{2}-\mathrm{V}_{\mathrm{e}}^{2}}{\text { 2.g.c }} \\
& \mathrm{P}=\mathrm{m} \cdot\left(\frac{\mathrm{V}_{\mathrm{i}}^{2}-\mathrm{V}_{\mathrm{e}}^{2}}{2 \cdot \mathrm{g} \cdot \mathrm{c}}\right) \\
& =\frac{1}{2 \cdot g \cdot c} \cdot \text { s.A. } V_{t}\left(V_{i}^{2}-V_{e}^{2}\right) \\
& \therefore P=\frac{1}{4 \cdot g \cdot c} \cdot \text {. .A. }\left(\mathrm{V}_{\mathrm{i}}+\mathrm{V}_{\mathrm{e}}\right) \cdot\left(\mathrm{V}_{\mathrm{i}}^{2}-\mathrm{V}_{\mathrm{e}}^{2}\right) \\
& \frac{\mathrm{dP}}{\mathrm{dV}_{\mathrm{e}}}=0 \\
& \Longrightarrow \mathrm{V}_{\mathrm{e}}=\frac{1}{3} \cdot \mathrm{V}_{\mathrm{i}} \\
& \Longrightarrow \mathrm{P}_{\max }=\frac{8}{27} \text {.s.A. } \mathrm{V}_{\mathrm{i}}^{3} \\
& =\frac{16}{27} \cdot\left(\frac{1}{2} \cdot \text { s. A. } \mathrm{V}_{\mathrm{i}}^{3}\right) \\
& P_{\text {max }}=0.593 \mathrm{P}_{\text {total }} \\
& \mathrm{C}_{\mathrm{p}}=\frac{\mathrm{P}_{\max }}{\mathrm{P}_{\text {available }}{ }^{2}}<0.593 \\
& \mathrm{~T}=\frac{\mathrm{P}}{\omega}=\frac{\mathrm{P}}{\pi \cdot \mathrm{D} \cdot \mathrm{N}} \quad \mathrm{N}=r p s \\
& \mathrm{D}=\sqrt{\frac{4}{\pi}} \cdot \mathrm{A} \\
& \eta=\frac{P}{P_{\text {total }}} \\
& \mathrm{P}=\eta \cdot\left(\frac{1}{2 \cdot \mathrm{g} \cdot \mathrm{c}} \cdot \zeta \cdot \mathrm{A} \cdot \mathrm{V}_{\mathrm{i}}^{3}\right) \\
& \mathrm{T}=\eta \cdot \frac{1}{2 \cdot \mathrm{g} \cdot \mathrm{c}} \cdot \frac{\text { s.A. } \mathrm{V}_{\mathrm{i}}^{3}}{\pi \cdot \mathrm{D} \cdot \mathrm{N}} \\
& \eta \eta \frac{1}{2 . g \cdot c} \cdot \frac{\varsigma \cdot \pi}{4} \cdot \frac{\pi \cdot D^{2} \cdot V_{i}^{3}}{\pi \cdot D \cdot N} \\
& \mathrm{~T}=\eta \cdot \frac{1}{\text { 8.g.c }} \cdot \frac{\text { s.D. } \mathrm{V}_{\mathrm{i}}{ }^{3}}{\mathrm{~N}} \\
& \eta_{\max }=\frac{16}{27} \\
& \mathrm{~T}_{\max }=\frac{2}{27 \cdot \mathrm{g} \cdot \mathrm{c}} \cdot \frac{\text { s.D. } \mathrm{V}_{\mathrm{i}}^{3}}{\mathrm{~N}}
\end{aligned}
$$




$$
\begin{aligned}
& \mathrm{F}_{\mathrm{x}}=\frac{1}{2 \cdot \mathrm{g} \cdot \mathrm{c}} \cdot \varsigma \cdot \mathrm{A}\left(\mathrm{V}_{\mathrm{i}}^{2}-\mathrm{V}_{\mathrm{e}}^{2}\right) \\
& \mathrm{F}_{\mathrm{x}}=\frac{\pi \cdot \mathrm{c} \cdot \mathrm{D}^{2}}{\text { 8.g.c }}\left(\mathrm{V}_{\mathrm{i}}{ }^{2}-\mathrm{V}_{\mathrm{e}}^{2}\right) \ldots \ldots .
\end{aligned}
$$

For $\mathrm{V}_{\mathrm{e}}=\frac{1}{3} \cdot \mathrm{V}_{\mathrm{i}}$

$$
\begin{aligned}
\Longrightarrow \mathrm{F}_{\mathrm{x}, \max } & =\frac{4}{9 \cdot \mathrm{g} \cdot \mathrm{c}} \varsigma \cdot \mathrm{A} \cdot \mathrm{V}_{\mathrm{i}}^{2} \\
\mathrm{~F}_{\mathrm{x}, \max } & =\frac{\pi}{9 \cdot \mathrm{g} \cdot \mathrm{c}} \varsigma \cdot \mathrm{D}^{2} \cdot \mathrm{V}_{\mathrm{i}}{ }^{2}
\end{aligned}
$$

$\mathrm{n}_{\omega}<5 \mathrm{Kph}$

$\mathrm{V}_{\mathrm{c}}=$ cut in speed

$\mathrm{V}_{\mathrm{f}}=$ furling speed

$\mathrm{V}_{\mathrm{d}}=$ design speed

Small - scale $<2 \mathrm{K \omega}$

Medium $2-100 \mathrm{~K} \omega$

Large size $>100 \mathrm{~K} \omega$

In this paper, we are considering the Savonius or ' $\mathrm{S}$ ' type Rotor for low speed of wind for Vertical Axis Wind Turbine. In terms of efficiency of Savonius type turbines have been found to be superior than other types of vertical types turbines[1].

Technical parameters for the systems of Modular design of WT-UPS for domestic appliances:

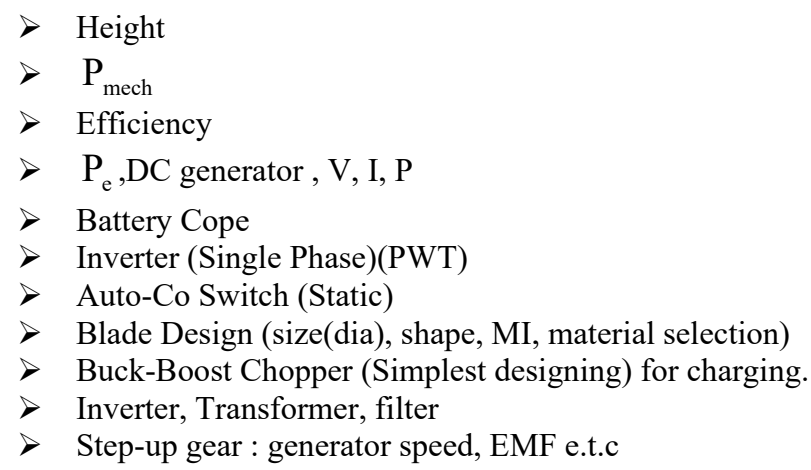

Gilbert's limit or Betz coefficient

$$
\begin{aligned}
> & \left(=\frac{16}{27}=0.593 \text { or } 59.3 \%\right) \text { of } \mathrm{P}_{\text {total }} \text { is recoverable } \\
\mathrm{P}_{\max } & =0.593 \cdot \frac{1}{2} \cdot \varsigma \cdot \mathrm{A}_{\mathrm{bl}} \cdot\left(\mathrm{u}_{\mathrm{w}}\right)_{\mathrm{us}}{ }^{3}
\end{aligned}
$$

\section{Savorins type VAWT}

- NO yaw control

- No gravity load on the rotor 
2 - blade Propeller

$$
\begin{aligned}
& \mathrm{S}(\text { solidity })=\frac{\mathrm{N} \cdot \mathrm{b}}{\pi \cdot \mathrm{D}} \\
& =\left(\frac{2 \times 6^{\prime \prime}}{\pi \times 48^{\prime \prime}}\right) \\
& \mathrm{u}_{\mathrm{w}}=6 \mathrm{~m} / \mathrm{s}, \mathrm{D}=1 \mathrm{~m}, \mathrm{~N}=45 \mathrm{rpm} \\
& \varsigma=\frac{\mathrm{P}}{\mathrm{R} \cdot \mathrm{T}}=1.205 \mathrm{Kg} / \mathrm{m}^{3} \\
& \mathrm{P}_{\text {total }}=\frac{\mathrm{P}_{\text {total }}}{\mathrm{A}_{\mathrm{bl}}}=\frac{1}{2} \cdot \varsigma \cdot\left(\mathrm{u}_{\mathrm{w}}\right)_{\mathrm{us}}{ }^{2} \\
& =\frac{1}{2} \times 1.205 \times 6^{3} \\
& =130.14 \mathrm{w} / \mathrm{m}^{2}
\end{aligned}
$$

Power Density Max

$$
\begin{gathered}
=\frac{8}{27} \cdot \varsigma \cdot(\mathrm{u})^{3} \\
=\frac{8}{27} \times 1.205 \times 6^{3} \\
=77 \mathrm{w} / \mathrm{m}^{2} \\
\eta=35 \% \\
\mathrm{P}_{\text {Density }}=\frac{\mathrm{P}}{\mathrm{A}_{\mathrm{bl}}}=35 \% \times 130.14 \\
=45 \mathrm{w} / \mathrm{m}^{2} \\
\mathrm{P}_{\text {total }}=45 \times \frac{\pi \cdot \mathrm{D}^{2}}{4} \\
=45 \times \frac{\pi \cdot 2^{2}}{4} \\
=143 \mathrm{~W}
\end{gathered}
$$

It is to be noted that Buck-boost chopper and charging circuit for batteries for each module are to be provided as per requirement.

DC generator

- 4 wind-turbines for each home, on the roof top

4 x 143 Watt Mechanical power $\rightarrow$ input to 4 DC generator

$$
\begin{aligned}
& \mathrm{E}=\frac{\mathrm{P} \cdot \varphi \cdot \mathrm{Z} . \mathrm{N}}{60 . \mathrm{A}} \\
& 12=\frac{4 \times 0.0188 \times 200 \times \mathrm{N}}{4 \times 60} \\
& 12=0.06266 \cdot \mathrm{N} \\
& \mathrm{N}=191.5 \approx 192 \mathrm{rpm}
\end{aligned}
$$


Gear ratio : $40 \mathrm{rpm}=192 \mathrm{rpm}$

12-V Req DC power(Battery) supply

Genenrator efficiency $75 \% \quad 140 \times 0.75=105 \mathrm{~W}$

Buck-Boost chopper fed battery

$105=12 \mathrm{~V} \times \mathrm{I}$

$\mathrm{I}=8.75 \mathrm{~A}$

It is to be noted that a standard $\mathrm{VCO}$ (voltage control oscillator) is be for generator of pulses for Buck-Boost converter.

A complete modular design for WT based domestic UPS (system)[ conventional symbols are used for all kinds of physical parameters] :

Computation of force and torque on the turbine blades:

$$
\begin{aligned}
& \mathrm{F}_{\max (\mathrm{x})}=\frac{\pi}{9} \cdot \varsigma \cdot \mathrm{D}^{2} \cdot \mathrm{u}^{2} \\
& =\frac{\pi}{9} \times 1.205 \times 4^{2} \times 5^{2} \\
& =42.04 \mathrm{~N} \\
& \mathrm{r}=0.5 \mathrm{~m} \\
& \mathrm{~T}_{\max }=\mathrm{F}_{\max } \times 0.5 \\
& \frac{60}{2 . \pi \cdot \mathrm{N}} \times 140=42 \times 0.5 \\
& \quad=21 \\
& \mathrm{~N}=\left(\frac{60 \times 140}{2 \pi \times 21}\right) \\
& \mathrm{N}=64 \mathrm{rpm} \quad 1: 6(\text { gear }) \\
& \mathrm{f} 24 \mathrm{~V} \rightarrow \quad 192 \times 2=384 \\
& \quad 64 \mathrm{rpm}: 384 \mathrm{rpm} \\
& 1
\end{aligned}
$$

Chopper \& VCO ( designing )

IC 723 / LM311 will work for output : $150 \mathrm{~mA}, 7-37 \mathrm{~V} \&$ input : $24 \mathrm{~V}$

\section{$24 \mathrm{~V}$ battery system}

DC side : $300 \mathrm{VA} \times 0.85=255 \mathrm{w}$

$$
\begin{aligned}
& \text { 1. } 24 \mathrm{~V} \mathrm{AC}(1: 10) \mathrm{Xform} \\
& \text { 2. } \frac{300 \mathrm{VA}}{24 \mathrm{~V}}=12.5 \mathrm{~A}
\end{aligned}
$$

$\mathrm{E}=24 \mathrm{~V} \times 1 \mathrm{~A} \times 1 \mathrm{hr}=24 \mathrm{whr}$

$\mathrm{Ah}=1 \mathrm{~A} \times 1 \mathrm{hr}$

$300 \mathrm{VA} \times 24 \mathrm{hr}=24 \times 1 \times 24 \mathrm{hr}$

$$
=576 \text { watt }- \text { hour }
$$

$\mathrm{E}=24 \mathrm{~V} \times 12.5 \mathrm{~A} \times 24 \mathrm{hr}$

$$
=7200 \mathrm{VAhr}
$$

$$
=7200 \mathrm{Watt}-\mathrm{hr}
$$

Battery $\rightarrow \mathrm{Ah} \rightarrow 300 \mathrm{Ah}$

300Ah,24V $\rightarrow 5000 /-$

DC generator $\rightarrow 4000 /-$ 


$$
\begin{aligned}
& \mathrm{P}=\mathrm{V} \times \mathrm{I} \times \cos \theta \\
& 255=240 \times \mathrm{I} \times 0.85 \\
& \mathrm{I}=1.25 \mathrm{~A} \quad(\mathrm{AC}) \\
& \mathrm{D}=3 \mathrm{~m} \\
& \mathrm{E}=\frac{\mathrm{P} \Phi \mathrm{N}}{60 \mathrm{~A}} \\
& 24=\frac{8 \times 0.01 \times 200 \times \mathrm{N}}{60 \times 2} \text { (wave winding) } \\
& 24=0.133 \mathrm{~N} \\
& \mathrm{~N}=180 \mathrm{rpm} \\
& 30 \mathrm{rpm}: 180 \mathrm{rpm} \text { (gear ratio) }
\end{aligned}
$$

Buck-Boost Chopper design for WTUPS is available in any standard textbook on Power Electronics and we are not including such details in our paper.

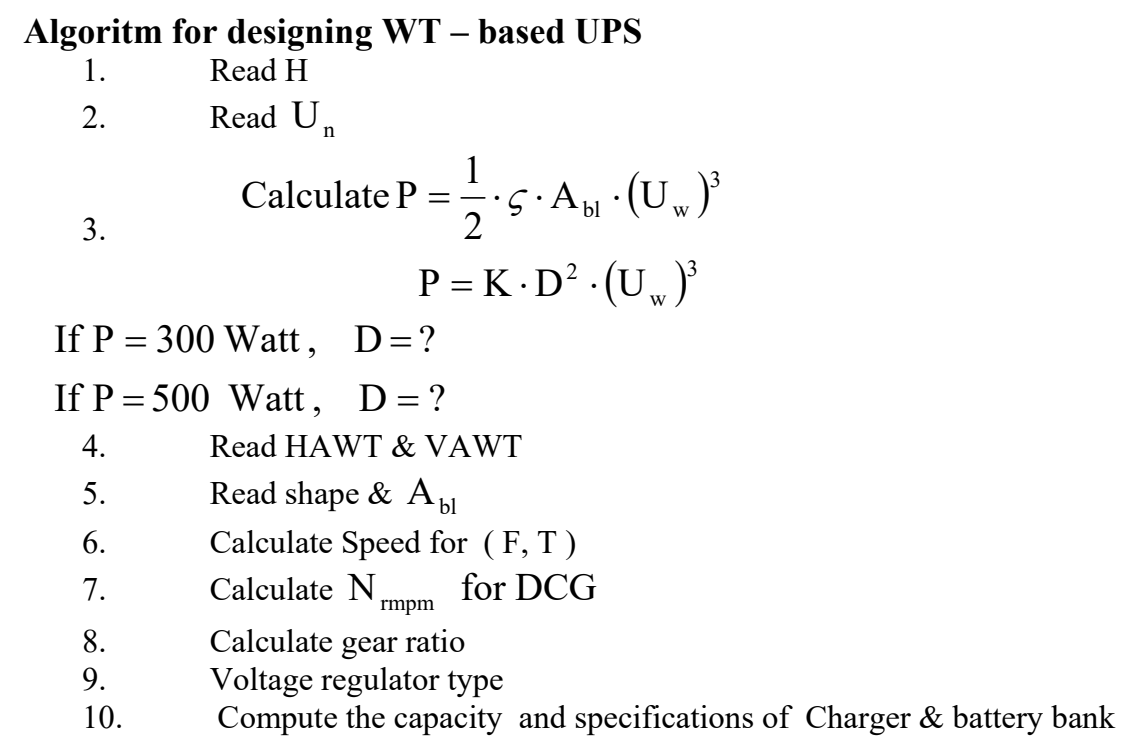

\section{Designingof a basic inverter circuits:-}

The data in hand are:

Primary Voltage $=230$ Volts, Secondary Current (Output Current) $=10$ Amps.

Secondary Voltage (Output Voltage) $=12-0-12$ volts, that is equal to 24 volts.

\section{Conclusions}

The basic idea is to feed power from a wind-turbine system to an Uninterrupted power supply for critical loads of any home. Hence wind-turbine, gear mechanism, DC generator, buck-boost DC-DC chopper, charger and battery bank need to be designed and specified with all types of compatibility considerations. It is felt that wind power, available totally free, can be harnessed to be stored in electrical battery bank and this could connected to an inveter to supply power to critical loads throughout the day. Unlike the solar energy, this energy will be available for 24 hours a day and it can be shown through calculations that the cost of installation of such a systemcould easily be recovered from the generated power in a span of roughly two years and this could be considered as a source of 
green energy for all homes. Such type of power system will be great step forward towards minimization of environmental pollution in the form of emission of green house gases.

There are several applications where even a temporary power failure can cause a great deal of public inconvenience leading to large economic losses . Examples of such applications are major computer installations, process control in comical plants, safety monitors, general communication systems, hospital intensive care units etc. For such critical loads, it is of paramount importance to provide an uninterruptable power supply(UPS) system so as to maintain the continuity of supply in case of power outages .

Mainly UPS system are two types: Namely off line system UPS and online system UPS. In off line system, under normal circumstances, normally on contacts are closed and normally off contacts are open and the mainly supply delivers ac power to the load. At the same time, the rectifier supplies continuous trickle charge to batteries to keep them fully charged. In the event of power outage, normally-off switch is turned on and the batteries deliver ac power to critical load through the inverter and the filter. A momentary interruption in the supply $(4-5 \mathrm{~m} \mathrm{sec})$ to the load can be observed in case lamps, fluorescent tubes, are a part of the load.

In online system, under normal circumstances main ac supply is rectified and the rectifier delivers power to maintain required charge on the battery. Rectifier also supplies power to the inverter continuously which is then given to ac type load through filter and normally on switch.

In case of main supply failure, batteries at once take over with no break of supply to critical load.

The stand-by batteries in the UPS system are either nickel-cadmium (NC) or lead acid type. Nickel cadmium batteries have many advantages like-

(1) Non- corrosiveness

(2) Does not emit any explosive gas when charging

(3) Longer life.

But however, its cost is three times that of lead acid batteries.

We have used to design the 250 VA domestic UPS-PWM inverter circuit, step and step down transformer, rectifier, static switch.

\section{REFERENCES}

[1]. Pendharkar A., Komerath N. , (2013) “The low cost vertical axis wind turbine project”, proceedings of the 2013 Annual conference of the American Society of Engineering Education, Atlanta Georgia, USA, 2013

[2]. Mohammad M. Bashar (2014), Computational and Experimental Study on Vertical Axis Wind Turbine in Search for an Efficient Design

[3]. J.B. Gupta (2013) Electrical Power systems, Dhanpat Rai \& Sons

[4]. . J.B. Gupta (2013) Principles and performance of Electrical Machines, Dhanpat Rai \& Sons

[5]. P.S. Bimbhra(2014), Power Electronics 